\title{
Conhecimento e ensino: fundamentos para a nova reforma ${ }^{1}$
}

Lee S. Shulman

Professor aposentado

da Universidade de Stanford
Resumo: Shulman constrói seus fundamentos para a reforma do ensino numa ideia de ensino que enfatiza compreensão e raciocínio, transformação e reflexão. "A ênfase é justificada”, ele escreve, "pela determinação com que a pesquisa e a política pública tão flagrantemente ignoraram esses aspectos do ensino no passado." Para articular e justificar essa concepção, Shulman responde a quatro perguntas: Quais são as fontes da base de conhecimento para o ensino? Em que termos essas fontes podem ser conceituadas? Quais são os processos de raciocínio e ação pedagógicos? e Quais são as implicações para a política de ensino e a reforma educacional? As respostas - informadas pela filosofia, pela psicologia e por um corpo crescente de estudos de caso baseados em professores experientes e iniciantes - vão muito além das atuais premissas e iniciativas relacionadas à questão da reforma. 0 resultado para professores, pesquisadores e formuladores de políticas públicas redireciona o modo de entender o ensino e de formar e avaliar professores.

Palavras-chave: Formação de professores. Política educacional. Ensino. Didática.

\section{PRólogo: UM RETRATO do ESPECIALISTA}

Lee S. Shulman, "Knowledge and Teaching Foundations of the New Reform", a Harvard Educational Review, v. 57, n. 1, p. 1-22, primavera 1987 (Copyright by the President and Fellows of Harvard College). Traduzido e publicado com autorização. Tradução de Leda Beck e revisão técnica de Paula Louzano. 
Retratos bem-feitos da especialidade no ensino são raros. Embora existam muitas descrições de professores eficazes, a maioria delas concentra-se na gestão da sala de aula. Encontram-se poucas descrições ou análises de professores que prestam muita atenção não apenas na gestão dos alunos em sala, mas também na gestão das ideias dentro do discurso em sala de aula. As duas ênfases são necessárias para produzir retratos da boa prática que sejam guias suficientes para uma educação melhor. Vamos examinar um breve relato.

Nancy empregava essa estrutura conceitual em suas aulas, usando-a para guiar o sequenciamento do material e a formulação das perguntas. Ela ensinava

A veterana Nancy, que leciona Inglês há 25 anos, foi objeto de um estudo com professores experientes que vimos fazendo. A aula estava chegando perto do fim de um curso sobre o livro Moby Dick, que vinha sendo estudado há duas semanas. A observadora ficou muito impressionada com a profundidade do entendimento de Nancy sobre esse romance e com sua habilidade como pedagoga, à medida que ela documentava como Nancy ajudou um grupo de alunos do primeiro ano do ensino médio a captar os vários aspectos dessa obra-prima. Nancy era uma professora muito ativa, cujo estilo em sala de aula usava uma interação substancial com seus alunos, tanto por meio de leitura em voz alta como por meio de debates abertos. Ela era como um maestro de orquestra sinfônica, fazendo perguntas, testando visões alternativas, estimulando os tímidos e moderando os intempestivos. Não acontecia muita coisa em sala de aula que não passasse por Nancy, cujos comandos e caminhadas, estruturando e expandindo, controlavam o ritmo da vida em sala de aula.

Nancy caracterizava seu tratamento da literatura em termos de um modelo teórico geral que ela usava.

Basicamente, divido as habilidades de leitura em quatro níveis:

Nível 1 é simplesmente tradução. [...] É o entendimento do significado literal, denotativo, e muitas vezes, para os alunos, isso significa consultar o dicionário.

Nível 2 é o significado conotativo e ainda é preciso olhar para as palavras. [...] o que isso quer dizer, o que isso nos diz sobre o personagem? [...] Lemos A letra escarlate, de Nathaniel Hawthorne. $O$ autor descreve uma roseira no primeiro capítulo. O nível literal é: o que é uma roseira? Mais importante: o que uma roseira sugere? O que vem à mente, o que você imagina?

Nível 3 é o nível da interpretação. [...] É o resultado dos níveis 1 e 2. Se o autor está usando um símbolo, o que isso revela sobre sua visão da vida? Em Moby Dick, usei as botas como exemplo em sala de aula. As botas seriam o nível literal.

O que significa quando ele entra embaixo da cama? E os alunos respondem que ele 
está tentando esconder alguma coisa. O Nivel 3 seria: o que diz o autor, Herman Melville, sobre a natureza humana? Qual é o resultado disso? O que isso nos diz sobre o personagem?

Nível 4 é o que chamo de aplicação e avaliação. Quando ensino literatura, tento levar os alunos ao Nivel 4 e é aí que eles pegam a literatura e entendem que ela tem um significado para suas vidas. Onde veríamos isso acontecer em nossa própria sociedade? Como se comportariam as pessoas que conhecemos se estivessem fazendo o que fazem esses personagens? Como esta obra de literatura se parece com nossas experiências comuns como seres humanos? [...] Portanto, minha visão da leitura é basicamente levá-los do significado literal para algum significado na vida deles. Quando ensino literatura, estou sempre trabalhando esses niveis (GUDMUNDSDOTTIR, 1988).

essa estrutura explicitamente aos alunos ao longo do semestre, ajudandoos a empregá-la como uma escada para organizar o estudo individual dos textos, para monitorar os próprios pensamentos. Embora, como professora, mantivesse um controle estrito do discurso em sala de aula, seus objetivos de ensino visavam a liberar as mentes de seus alunos por meio do letramento, para que pudessem, enfim, usar grandes obras de literatura para iluminar suas próprias vidas. Qualquer que fosse a obra, ela sabia como organizar, enquadrar o ensino, dividi-lo adequadamente em lições de casa e atividades. Ela parecia ter um índice na cabeça dos livros sobre os quais havia ensinado tantas vezes - Moby Dick, A letra escarlate, A glória de um covarde (de Stephen Crane), As aventuras de Huckleberry Finn (de Mark Twain) -, com episódioschave organizados em sua mente para diferentes propósitos pedagógicos, diferentes níveis de dificuldade, diferentes tipos de alunos, diferentes temas ou ênfases. Sua combinação de domínio do conteúdo e habilidade pedagógica era deslumbrante.

Uma manhã, quando a observadora chegou à sala de aula, encontrou Nancy sentada à sua mesa, como sempre. Mas a resposta ao bom-dia foi um apenas um sorriso e um gesto em direção a um bloco de papel sobre a mesa. "Estou com laringite e não posso falar", dizia o bilhete. Pior, ela parecia estar com gripe, pois estava visivelmente com pouca energia. Para uma professora que gerenciava sua sala de aula por meio do poder de sua voz e de seu jeito, tratava-se quase de invalidez. Ou não?

Usando uma combinação de notas manuscritas e sussurros, ela dividiu a classe em pequenos grupos, por fileira, uma tática que já tinha usado duas vezes durante o curso. Cada grupo devia responder a uma série de questões sobre um personagem diferente, que tinha um papel proeminente nos primeiros 
capítulos do romance. Muito tempo foi usado no final desse período para que representantes de cada grupo reportassem seus resultados para toda a classe. Mais uma vez, a aula transcorreu pacificamente e o conteúdo foi tratado com cuidado. Mas o estilo mudara radicalmente, uma tecnologia de ensino completamente diferente tinha sido usada e, mesmo assim, os alunos estavam engajados e parece ter havido aprendizado.

Em seguida, vimos muitos outros exemplos do estilo flexível de Nancy, adaptado às características dos alunos, às complexidades do conteúdo e à sua própria condição física. Quando os alunos tinham sérios problemas com um texto específico, ela deliberadamente ficava nos níveis mais simples da escala de leitura, ajudando-os com os significados denotativos e conotativos, e enfatizando menos as interpretações literárias. Quando ensinou Huck Finn, um romance que considerava menos difícil do que Moby Dick, seu estilo mudou de novo. Deu muito mais autonomia aos alunos e não dirigiu tanto a sala de aula.

Para Huck Finn, ela deixou que os alunos aprendessem uns com os outros.

Organizou-os em oito grupos de múltiplas habilidades, cada um trabalhando um tema diferente: hipocrisia; sorte e superstição; ganância e materialismo; ideias românticas e fantasia; religião e a Bíblia; costumes e classe social; família, racismo e preconceito; liberdade e consciência. Houve apenas duas verificações de leitura no início e só duas rodadas de apresentações. Quando os grupos começaram a trabalhar, Nancy sentou-se no fundo da sala e só interagiu com os alunos quando solicitada e durante as apresentações dos grupos (GUDMUNDSDOTTIR, 1988).

Portanto, o padrão de instrução de Nancy, seu estilo de ensino, não é simplesmente uniforme ou previsível. Ela responde de maneira flexível à dificuldade e ao caráter do conteúdo, às capacidades dos alunos (que podem mudar até ao longo do mesmo curso) e aos seus propósitos educacionais. Ela pode não apenas reger a orquestra do púlpito, mas pode também se afastar e assisti-la tocando virtuosamente sozinha.

Quais são as crenças, concepções e práticas de Nancy e como ela sabe o que fazer para poder ensinar como ensina? Será que outros professores podem ser preparados para ensinar com tanta habilidade? A esperança de que ensinar como Nancy possa se tornar típico, em vez de raro, motiva muitos dos esforços para as reformas do ensino recentemente propostas. 


\section{AS NOVAS REFORMAS}

Ao longo do último ano, o público e os educadores profissionais têm tido acesso a vários relatórios sobre como melhorar o ensino, seja como atividade ou como profissão. Um dos temas recorrentes nesses relatórios tem sido a profissionalização do ensino - a elevação do ensino para o nível de uma ocupação mais respeitada, mais responsável, com mais e melhores remunerações. No entanto, a afirmação de que o ensino merece status profissional é baseada numa premissa mais fundamental: a de que os padrões pelos quais a educação e o desempenho dos professores devem ser julgados podem ser elevados e mais claramente articulados. Os defensores da reforma profissional baseiam seus argumentos na crença de que existe "uma base de conhecimento para o ensino" - um agregado codificado e codificável de conhecimento, habilidades, compreensão e tecnologias, de ética e disposição, de responsabilidade coletiva - e também um meio de representá-lo e comunicálo. Os relatórios do Grupo Holmes (1986) e da Força-Tarefa Carnegie (1986) repousam nessa crença e, além disso, afirmam que a base de conhecimento está crescendo. Argumentam que essa base deveria ser também a base da formação de professores e informar diretamente a prática de ensino.

A retórica relacionada à base de conhecimento, no entanto, raramente especifica o caráter desse conhecimento. Não diz o que os professores deveriam saber, fazer, entender ou dizer que tornasse o ensino algo mais do que uma forma de trabalho individual, quanto mais ser considerado entre as profissões que requerem formação acadêmica.

Neste ensaio, apresento um argumento relacionado a conteúdo, caráter e fontes para uma base de conhecimento e sugiro uma resposta para a questão da base intelectual, prática e normativa da profissionalização do ensino. As questões focalizadas pelo argumento são: quais são as fontes da base de conhecimento para o ensino? Em que termos podem ser conceituadas essas fontes? Quais são as implicações para uma política do ensino e para a reforma educacional?²

2 A maior parte do trabalho empírico sobre o qual repousa este ensaio foi conduzida com professores de escola secundária, tanto novatos como veteranos. Embora eu acredite firmemente que muito da ênfase encontrada aqui sobre a centralidade do conhecimento pedagógico do conteúdo também funciona razoavelmente bem para o nível primário, estou relutante em fazer essa afirmação taxativamente. Pesquisas em andamento sobre o nível primário, tanto por Leinhardt (1983) e seus colegas (por exemplo, LEINHARDT; GREENO, 1985; LEINHARDT; SMITH, 1986), como por nosso próprio grupo de pesquisa, devem esclarecer 0 assunto. 
Ao abordar essas questões, sigo a trilha aberta por muitos pesquisadores eminentes, inclusive Dewey (1904), Scheffler (1965), Green (1971), Fenstermacher (1978), Smith (1980) e Schwab (1983), entre outros. As discussões deles sobre quais qualidades e entendimentos, habilidades e capacidades, e quais traços e sensibilidades transformam alguém num professor competente têm ecoado nas salas de conferências de educadores por gerações. Minha abordagem também foi condicionada por dois projetos em andamento: um estudo sobre como os professores iniciantes aprendem a ensinar e uma tentativa de desenvolver um conselho nacional de ensino.

No primeiro caso, meus colegas e eu temos observado, ao longo dos últimos três anos, o aumento do conhecimento pedagógico e disciplinar por jovens homens e mulheres. Generosamente, eles permitiram observá-los e seguir suas agitadas jornadas, de quando eram estudantes em cursos de formação de professores até se tornarem professores neófitos. Na pesquisa, aproveitamos o tipo de percepção que Piaget oferece em suas investigações sobre o desenvolvimento do conhecimento. Ele descobriu que podia aprender muito sobre o conhecimento e seu desenvolvimento a partir da observação dos muito jovens - os que estavam apenas começando a desenvolver e organizar sua inteligência. Seguimos esse modelo ao estudar aqueles que começam a aprender a ensinar. Sua evolução, de estudantes a professores, de aprendizes a professores iniciantes, expõe e ilumina os complexos corpos de conhecimento e habilidades necessários para funcionar eficazmente como professor. 0 resultado é que erro, sucesso e refinamento - em uma palavra, o crescimento do conhecimento do professor - são vistos em relevo, em destaque e em câmera lenta. 0 tropeço do neófito torna-se a janela do pesquisador.

Ao mesmo tempo, encontramos e exploramos casos de professores veteranos como Nancy (Baxter, em preparação; Gudmundsdottir, 1988; Hashweh, 1985) para comparar com os dos novatos. O que esses estudos mostram é que o conhecimento, a compreensão e as habilidades que os principiantes exibem com hesitação, mas às vezes magistralmente, aparecem com facilidade no especialista. À medida que estudávamos nossos casos, sempre perguntávamos o que os professores sabiam (ou não) que lhes permitia ensinar de uma certa maneira.

No segundo caso, na maior parte do ano passado ${ }^{3}$, engajei-me em um projeto bem diferente, sobre o papel do conhecimento no ensino. Junto com a recente iniciativa Carnegie para a reforma da profissão docente, meus colegas e eu

3 O presente texto é de 1988, portanto, o autor se refere ao ano de 1987. (N. da T.) 
temos buscado jeitos para criar um conselho nacional de avaliação do ensino, bastante parecido com o Conselho Nacional de Examinadores Médicos ${ }^{4}$ (Shulman; Sykes, 1986; Sykes, 1986). Com esse desafio, as questões sobre definição e operacionalização do conhecimento no ensino tornam-se muito mais do que exercícios acadêmicos. Se os professores devem ser certificados com base em juízos e padrões bem fundamentados, então esses padrões em que se baseia um conselho nacional devem ser legitimados por três fatores: devem ser estreitamente ligados às pesquisas acadêmicas nas disciplinas que formam o currículo (como linguagem, física e história), assim como naquelas que são fundamentais no processo de educação (como psicologia, sociologia ou filosofia); devem ter credibilidade intuitiva junto à comunidade profissional em cujo interesse foi projetado; e devem conectar-se às concepções normativas apropriadas de ensino e de formação de professores.

As novas propostas de reforma partem de premissas sobre a base de conhecimento para o ensino: quando os defensores da reforma sugerem que deveria haver mais requisitos para a educação dos professores e que os períodos de aprendizado deveriam ser maiores, eles pressupõem que algo substancial precisa ser aprendido. Quando recomendam que os padrões sejam mais elevados e que se estabeleça um sistema de avaliação, eles pressupõem que deva existir um corpo de conhecimento e habilidades a ser examinado. Nossa pesquisa e a de outros (por exemplo, Berliner, 1986; Leinhardt; Greeno, 1986) identificaram as fontes e sugeriram esquemas dessa base de conhecimento. Observar veteranos como Nancy ensinar o mesmo material que é difícil para os professores novatos ajudou a focar nossa atenção nos tipos de conhecimento e aptidão necessários para bem ensinar materiais exigentes. Focando no ensino de tópicos específicos Huck Finn, equações de segundo grau, o subcontinente indiano, fotossíntese -, aprendemos como certos tipos também específicos de conhecimento de conteúdo e de estratégias pedagógicas necessariamente interagem na mente dos professores.

O que se segue é uma discussão das fontes e de estruturas da base de conhecimento requerida para o ensino. Divido esta discussão em duas análises distintas. Primeiro, depois de dar uma visão geral de uma possível

4 O National Board of Medical Examiners (NBME) desenvolve métodos e sistemas de avaliação profissional que, a partir de 1992, são utilizados pelos conselhos estaduais de medicina e pelo United States Medical Licensing Examination (Exame para Licença Médica dos Estados Unidos ou USMLE, na sigla em inglês). Uma vez formados, para obter um registro profissional e poder clinicar, os médicos estadunidenses devem se submeter a esse exame, de forma semelhante ao exame da Ordem dos Advogados do Brasil (OAB) para recém-formados em Direito. (N. da T.) 
estrutura de base de conhecimento para o ensino, examino as fontes dessa base de conhecimento, isto é, as áreas da pesquisa acadêmica e da prática didática das quais os professores podem extrair o conhecimento necessário. Em seguida, exploro os processos de raciocínio e ação pedagógicos dentro dos quais esse conhecimento do professor é usado.

\section{A BASE DE CONHECIMENTO}

Ao começar uma discussão sobre a base de conhecimento para o ensino, surgem imediatamente várias questões relacionadas: Qual base de conhecimento? Já se sabe o suficiente sobre o ensino para dar suporte a uma base de conhecimento? O ensino não será apenas um pouco mais do que estilo pessoal, boa comunicação, dominar algum conteúdo e aplicar os resultados de pesquisas recentes sobre eficácia do ensino? Só este último item - as conclusões de pesquisas sobre a eficácia do ensino - é geralmente considerado parte da base de conhecimento.

No passado, tanto as ações dos formuladores das políticas públicas como dos formadores de professores foram consistentes com a fórmula segundo a qual o ensino requer habilidades básicas, conhecimento de conteúdo e habilidades pedagógicas gerais. Avaliações de professores na maioria dos estados americanos consistem em algum tipo de combinação de testes de habilidades básicas, um exame de competência no conteúdo ensinado e observações de aula para garantir a presença de certas condutas gerais de ordem pedagógica. Dessa forma, eu diria que o ensino é trivializado, suas complexidades são ignoradas e suas demandas, reduzidas. Os próprios professores têm dificuldade para articular o que sabem e como o sabem.

Não obstante, no momento, as comunidades de formuladores de políticas públicas continuam acreditando que as habilidades necessárias ao ensino são aquelas identificadas na pesquisa empírica sobre eficácia do ensino. Essa pesquisa, sumarizada por Brophy e Good (1986), Gage (1986) e Rosenshine e Stevens (1986), foi conduzida dentro da tradição de pesquisa psicológica. Ela parte da premissa de que o desempenho humano em situações específicas pode ser entendido em termos do funcionamento de processos genéricos subjacentes. Em um estudo do contexto do ensino, a pesquisa, portanto, busca identificar as formas gerais de conduta pedagógica que se correlacionam com o desempenho dos alunos em testes padronizados, tanto em estudos 
experimentais como naqueles descritivos. Os pesquisadores que conduzem a investigação reconhecem que simplificações importantes precisam ser feitas, mas acreditam que são etapas necessárias na condução de estudos científicos. Aspectos fundamentais do ensino, como o conteúdo lecionado, o contexto em sala de aula, as características físicas e psicológicas dos alunos ou a realização de propósitos não necessariamente avaliados por testes padronizados são tipicamente ignorados na busca pelos princípios gerais do ensino eficaz.

Quando os formuladores de políticas públicas buscaram definições do bom ensino "fundamentadas em pesquisas" para servir como base das avaliações de professores e dos sistemas de observação em sala de aula, as listas de condutas docentes identificadas como eficazes em pesquisas empíricas transformaram-se em competências desejáveis para professores em sala de aula. Tornaram-se itens das avalições ou das escalas de referência para observação em sala de aula. Foram legitimadas porque "confirmadas pela pesquisa". Embora os pesquisadores entendessem que seus resultados eram simplificados e incompletos, a comunidade de formuladores de políticas públicas aceitou-os como suficientes para as definições dos padrões.

Por exemplo: algumas pesquisas indicaram que os alunos tinham desempenho melhor quando eram explicitamente informados pelo professor sobre o objetivo da aula. Isso parece ser um resultado perfeitamente razoável. Mas, quando foi incorporado pela política pública, as escalas de avaliação de competências para observação em sala de aula perguntavam se o professor tinha, no início da aula, escrito os objetivos no quadro-negro e/ou se tinha explicado esses objetivos diretamente aos alunos. Se o professor não tivesse feito nada disso, anotava-se que ele falhara na demonstração de uma competência desejável. Nenhum esforço era feito para descobrir se a não comunicação do objetivo poderia ser consistente com o plano da aula em questão.

Além disso, os que concordam com a divisão entre o conteúdo e os processos de ensino novamente introduziram na política pública o que havia sido um mero ato de conveniência acadêmica e simplificação por parte dos pesquisadores. Processos de ensino foram observados e avaliados sem referência alguma à adequação ou precisão das ideias transmitidas. Em muitos casos, não se exigia que os observadores fossem especialistas no conteúdo das áreas em observação, porque não interessava para a classificação do desempenho docente. Assim, o que pode ter sido uma estratégia aceitável para a pesquisa tornou-se uma política inaceitável para a avaliação de professores. 
Neste ensaio, argumento que os resultados da pesquisa sobre eficácia do ensino, embora válidos, não são a única fonte de informação para definir a base de conhecimento para o ensino. Essas fontes deveriam ser entendidas como muito mais ricas e abrangentes. Na verdade, compreendidas adequadamente, as fontes verdadeiras e potenciais de uma base de conhecimento para o ensino são tantas que nossa pergunta não deveria ser: "Há mesmo muita coisa que é preciso saber para ensinar?" Em vez disso, a pergunta deveria expressar nosso espanto: “Como é possível aprender tudo que é preciso saber sobre o ensino durante o breve período destinado à formação de professores?" A maior parte do restante deste ensaio detalha o argumento de que existe sim uma base de conhecimento para lecionar já produzida.

\section{Uma visão do ensino}

Começo com a formulação de que a capacidade para ensinar centra-se ao redor dos seguintes lugares-comuns do ensino, parafraseados de Fenstermacher (1986). Um professor sabe alguma coisa não sabida por outrem, presumivelmente os alunos. Um professor pode transformar a compreensão de um conteúdo, habilidades didáticas ou e valores em ações e representações pedagógicas. Essas ações e representações se traduzem em jeitos de falar, mostrar, interpretar ou representar ideias, de maneira que os que não sabem venham a saber, os que não entendem venham a compreender e discernir, e os não qualificados tornem-se qualificados. Portanto, o ensino necessariamente começa com o professor entendendo o que deve ser aprendido e como deve ser ensinado. Ele procede com uma série de atividades, durante as quais os alunos recebem instruções e oportunidades específicas para aprender ${ }^{5}$, embora 0 aprendizado propriamente dito seja, em última análise, de responsabilidade dos alunos. 0 ensino conclui com uma nova

\footnotetext{
Há muitos aspectos infelizes nessa formulação, nem que seja apenas pela impressão que dão. A retórica da análise, por exemplo, não pretende sugerir que a educação se reduz à transmissão de conhecimento, a passagem de informação de um professor ativo para um aluno passivo, ou que essa informação seja vista como produto em vez de processo. Minha concepção do ensino não se limita à instrução direta. De fato, minha afinidade pelo aprendizado por meio da descoberta e pelo ensino inquiridor é não apenas entusiástica, mas também antiga (ver, por exemplo, Shulman e Keislar, 1966). Mas mesmo nessas formas de educação centradas no aluno, em que a maior parte da iniciativa está nas mãos dos alunos, há pouco espaço para a ignorância do professor. Com efeito, temos razões para acreditar que a compreensão do professor é ainda mais crucial para a sala de aula orientada à investigação do que para sua alternativa didática. Que os alunos aprendam a compreender e resolver problemas, a pensar crítica e criativamente, e que também aprendam fatos, princípios e regras de procedimento são objetivos centrais no meu conceito de ensino. Finalmente, entendo que o aprendizado do conteúdo da disciplina muitas vezes não é um fim em si mesmo, mas um veículo a serviço de outras metas. Não obstante, pelo menos no nível secundário, a disciplina é um veículo quase universal para instrução, qualquer que seja a meta final.
} 
compreensão tanto do professor como do aluno ${ }^{6}$. Embora seja certamente uma concepção essencial do ensino, ela também é uma concepção incompleta. 0 ensino deve ser adequadamente entendido como algo mais do que a melhoria da compreensão; mas, se não for nem mesmo isso, então serão discutíveis as questões relacionadas ao desempenho de suas outras funções. 0 próximo passo é delinear as categorias de conhecimento subjacentes à compreensão do professor, que é necessária para promover a compreensão entre os alunos.

\section{Categorias da base de conhecimento}

Se o conhecimento do professor fosse organizado num manual, numa enciclopédia ou em algum outro formato de aglomeração de conhecimento, como seriam os títulos das categorias ${ }^{7}$ ? No mínimo, deveriam incluir:

- conhecimento do conteúdo;

- conhecimento pedagógico geral, com especial referência aos princípios e estratégias mais abrangentes de gerenciamento e organização de sala de aula, que parecem transcender a matéria;

- conhecimento do currículo, particularmente dos materiais e programas que servem como "ferramentas do ofício" para os professores;

- conhecimento pedagógico do conteúdo, esse amálgama especial de conteúdo e pedagogia que é o terreno exclusivo dos professores, seu meio especial de compreensão profissional;

- conhecimento dos alunos e de suas características;

- conhecimento de contextos educacionais, desde o funcionamento do grupo ou da sala de aula, passando pela gestão e financiamento dos sistemas educacionais, até as características das comunidades e suas culturas; e

- conhecimento dos fins, propósitos e valores da educação e de sua base histórica e filosófica.

6 Esta formulação é extraída da perspectiva do professor e, portanto, deve ser vista por alguns leitores como excessivamente centrada no professor. Não pretendo diminuir a centralidade do aprendizado do aluno para o processo educacional, nem a prioridade que deve ser dada ao aprendizado do aluno em relação à compreensão do professor. Mas nossas análises do ensino eficaz devem reconhecer que os resultados para os professores, assim como para os alunos, devem ser considerados em qualquer tratamento adequado dos resultados educacionais.

7 Tentei fazer esta lista em outras publicações, embora não tenha alcançado grande consistência entre os artigos (por exemplo, SHULMAN, 1986b; SHULMAN; SYKES, 1986; WILSON; SHULMAN; RICHERT, 1987). 
Entre essas categorias, o conhecimento pedagógico do conteúdo é de especial interesse, porque identifica os distintos corpos de conhecimento necessários para ensinar. Ele representa a combinação de conteúdo e pedagogia no entendimento de como tópicos específicos, problemas ou questões são organizados, representados e adaptados para os diversos interesses e aptidões dos alunos, e apresentados no processo educacional em sala de aula. O conhecimento pedagógico do conteúdo é, muito provavelmente, a categoria que melhor distingue a compreensão de um especialista em conteúdo daquela de um pedagogo. Embora se possa dizer muito mais sobre as categorias da base de conhecimento para o ensino, elucidá-las não é o principal propósito deste ensaio.

\section{Enumeração das fontes}

Há pelo menos quatro grandes fontes para a base de conhecimento para o ensino: (1) formação acadêmica nas áreas de conhecimento ou disciplinas; (2) os materiais e o entorno do processo educacional institucionalizado (por exemplo, currículos, materiais didáticos, organização e financiamento educacional, e a estrutura da profissão docente); (3) pesquisas sobre escolarização, organizações sociais, aprendizado humano, ensino e desenvolvimento, e outros fenômenos sociais e culturais que afetam o que os professores fazem; e (4) a sabedoria que deriva da própria prática. Permitamme estender-me sobre cada uma dessas fontes.

Formação acadêmica nas áreas de conhecimento ou disciplinas. A primeira fonte da base de conhecimento é o conhecimento do conteúdo - conhecimento, compreensão, aptidão e disposição que devem ser adquiridos pelos alunos. Esse conhecimento repousa sobre duas fundações: a bibliografia e os estudos acumulados nas áreas de conhecimento, e a produção acadêmica histórica e filosófica sobre a natureza do conhecimento nesses campos de estudo. Por exemplo, o professor de linguagem deveria conhecer prosa e poesia, o uso e a compreensão da língua escrita e falada, e gramática. Além disso, ele ou ela deveria estar familiarizado com a literatura crítica de certos romances ou épicos em discussão em sala de aula. Também deveria entender teorias alternativas de interpretação e crítica, e como elas podem se relacionar com questões de currículo e de ensino.

O ensino é, essencialmente, uma profissão que exige formação acadêmica. 0 professor é um membro da comunidade acadêmica. Ele ou ela deve entender as estruturas da disciplina, os princípios da organização conceitual e os 
princípios da investigação que ajudam a responder a dois tipos de perguntas em cada área de conhecimento: quais são as ideias e habilidades importantes desta área? E como são acrescentadas as novas ideias e abandonadas outras ideias consideradas deficientes pelos que produzem conhecimento nesta área? Em outras palavras, quais são as regras e procedimentos da boa pesquisa ou produção acadêmica na área? Essas questões são paralelas ao que Schwab (1964) caracterizou como conhecimento de estruturas substantivas e sintáticas, respectivamente. Esta visão das fontes relacionadas ao conteúdo do conhecimento necessariamente implica que o professor deve ter não apenas profundidade de compreensão das matérias específicas que ensina, mas também uma educação humanista abrangente, que serve para enquadrar o já aprendido e facilitar a nova compreensão. 0 professor tem responsabilidades especiais com relação ao conhecimento do conteúdo, pois serve como fonte primária da compreensão deste pelo aluno. A maneira como essa compreensão é comunicada transmite aos alunos o que é essencial e o que é periférico na matéria. Diante da diversidade dos alunos, o professor deve ter uma compreensão flexível e multifacetada, adequada à oferta de explicações diferentes dos mesmos conceitos ou princípios. Conscientemente ou não, o professor também transmite ideias sobre como a "verdade" é determinada numa área e um conjunto de atitudes e valores que influenciam notoriamente a compreensão do aluno. Essa responsabilidade demanda especialmente a profundidade de compreensão do professor das estruturas da matéria, assim como suas atitudes e entusiasmo com relação ao que está sendo ensinado e aprendido. Esses vários aspectos do conhecimento do conteúdo, portanto, são devidamente entendidos como uma característica central da base de conhecimento para o ensino.

Estruturas e materiais educacionais. Para atingir os objetivos da escolarização organizada, criam-se materiais e estruturas para ensinar e aprender. Entre eles, incluem-se os currículos, com seus escopos e sequências didáticas; as avaliações e os materiais relacionados; instituições com suas hierarquias e seus sistemas explícitos e implícitos de regras e papéis; organizações profissionais de professores, com suas funções de negociação, mudança social e proteção mútua; agências governamentais em todos os níveis, do distrito escolar ao estado e à federação; e mecanismos gerais de gestão e finanças. Os professores necessariamente operam dentro de uma matriz criada por esses elementos, usando-os e sendo usados por eles, portanto é lógico que os princípios, as políticas e os fatos relacionados ao seu funcionamento devem compor uma 
fonte fundamental da base de conhecimento para o ensino. Não é preciso sustentar que uma literatura específica respalda esta fonte de conhecimento, embora certamente exista abundante bibliografia de pesquisa na maioria dessas áreas. Mas, se um professor precisa "conhecer o território" do ensino, então deve estar familiarizado com o cenário desses materiais, instituições, organizações e mecanismos, o que inclui tanto as ferramentas do ofício como as condições contextuais que vão facilitar ou inibir os esforços para ensinar.

Formação acadêmica formal em educação. Uma terceira fonte é o importante e crescente corpo de literatura acadêmica devotada à compreensão dos processos de escolarização, ensino e aprendizado. Essa literatura inclui os resultados e os métodos da pesquisa empírica nas áreas de ensino, aprendizado e desenvolvimento humano, assim como os fundamentos normativos, filosóficos e éticos da educação.

Os aspectos normativos e teóricos do conhecimento acadêmico sobre o ensino são, talvez, os mais importantes. Infelizmente, os formuladores de políticas educacionais e os responsáveis pela formação de professores tendem a tratar apenas os resultados da pesquisa empírica sobre ensino e aprendizado como porções relevantes da base de conhecimento acadêmico. Mas esses resultados, embora sejam importantes e mereçam estudo cuidadoso, representam apenas uma faceta da contribuição acadêmica. Talvez as influências mais duradouras e poderosas da academia nos professores sejam aquelas que enriquecem suas imagens do possível: suas visões do que constitui uma boa educação ou de como seria um jovem bem-educado se recebesse o estímulo e as oportunidades apropriadas.

Todas as obras de Platão, Dewey, Neill e Skinner comunicam suas concepções do que seria um bom sistema educacional. Além disso, muitos dos trabalhos escritos para disseminar principalmente os resultados da pesquisa empírica também servem como fontes importantes desses conceitos. Incluo entre esses trabalhos como o de Bloom (1976), sobre os diferentes níveis de complexidade da aprendizagem, e o de Rosenthal e Jacobson (1968), sobre expectativas docentes. Independentemente de saber se os resultados empíricos desses livros têm fundamento, é inegável o impacto deles nas concepções de professores sobre os objetivos possíveis e desejáveis da educação. Portanto, a literatura filosófica, crítica e empírica que pode informar os objetivos, visões e sonhos dos professores é uma parte considerável da base de conhecimento acadêmico sobre o ensino. 
Um tipo de conhecimento acadêmico citado com mais frequência resulta do estudo empírico da eficácia do ensino. Essa pesquisa foi sumarizada recentemente por Gage $(1978,1986)$, Shulman (1986a), Brophy e Good (1986) e Rosenshine e Stevens (1986). A meta essencial desse tipo de pesquisa tem sido identificar os comportamentos e estratégias docentes que, com maior probabilidade, levam a ganhos de desempenho entre os alunos. Como a pesquisa focou em relações genéricas - comportamentos docentes associados com ganhos acadêmicos discentes, independentemente da disciplina ou da série escolar -, os resultados são muito mais conectados com a gestão de sala de aula do que com as sutilezas da pedagogia de cada área . Ou seja, os princípios do ensino eficaz tratam de transformar as salas de aula em lugares onde os alunos podem cuidar de tarefas instrucionais, orientando-se a si mesmos para aprender com o mínimo possível de interrupções e distrações, e receber uma oportunidade justa e adequada para aprender. Além disso, os propósitos educacionais para os quais os resultados dessas pesquisas são mais relevantes constituem-se no ensino de habilidades. Rosenshine (1986) observou que a pesquisa sobre o ensino eficaz tem muito pouco a oferecer ao ensino da compreensão, especialmente quando se trata de um conteúdo escrito mais complexo; portanto, esse tipo de pesquisa se aplica melhor ao ensino de uma habilidade como a multiplicação do que ao ensino de interpretações críticas de 0 federalista ${ }^{8}$, por exemplo.

Há cada vez mais princípios genéricos desse tipo para o ensino eficaz, e já foram até incorporados em avaliações de professores como o Exame Nacional de Professores e em avaliações estaduais do desempenho docente durante 0 período probatório. Seu ponto fraco - o fato de que essencialmente ignoram que o ensino tem um caráter específico para cada disciplina - é também seu ponto forte. Descobrir, explicitar e codificar princípios gerais do ensino simplifica uma atividade que é escandalosamente complexa. 0 grande perigo ocorre, porém, quando um princípio geral do ensino é distorcido para se transformar em prescrição, quando a máxima se torna uma ordem. Os estados que adotaram princípios práticos do ensino, com base exclusivamente em estudos empíricos da eficácia genérica do ensino, e os transformaram em critérios independentes e rígidos para julgar o valor de um professor, estão engajados num processo político que deverá enfraquecer, não aperfeiçoar, a profissão docente.

8 Conjunto de 85 artigos publicados em jornais do estado de Nova York entre 1787 e 1788, principalmente por Alexander Hamilton e James Madison, com argumentos para convencer a população a votar a favor da Constituição que acabara de ser redigida. Reunidos sob o título The Federalist Papers, esses textos são considerados uma das mais importantes contribuições ao pensamento político estadunidense. (N. da T.) 
Os resultados da pesquisa sobre aprendizado e desenvolvimento também caem dentro da área de descobertas da pesquisa empírica. Essa pesquisa difere dos estudos sobre o ensino por conta da unidade de análise. Estudos sobre o ensino ocorrem tipicamente em salas de aula convencionais. Já o aprendizado e o desenvolvimento são geralmente estudados na perspectiva dos indivíduos. Assim, estudos sobre o ensino relatam como os professores lidam com o inescapável caráter coletivo das escolas, lugares onde grupos de estudantes trabalham e aprendem em conjunto. Em contraste, estudos sobre aprendizado e desenvolvimento produzem princípios sobre o comportamento ou o pensamento individuais que muitas vezes precisam ser generalizados com cautela para serem úteis para a docência.

Nessas áreas, a pesquisa pode ser ao mesmo tempo genérica e específica para cada disciplina. Por exemplo, a pesquisa de psicologia cognitiva contribui para o desenvolvimento da compreensão de como a mente funciona para armazenar, processar e recuperar informação. Esse entendimento geral pode certamente ser fonte de conhecimento para professores, assim como o trabalho de Piaget, Maslow, Erikson ou Bloom tem sido e continua a ser. Também encontramos trabalhos extremamente úteis sobre disciplinas específicas e sobre os níveis de desenvolvimento do aluno nesta área; por exemplo, aprendemos sobre os equívocos dos alunos do primário nas aulas de aritmética (Erlwanger, 1975) ou sobre as dificuldades de estudantes universitários ou alunos do secundário para compreender princípios de física (por exemplo, CLEMENT, 1982). Os dois tipos de pesquisa contribuem para uma base de conhecimento para o ensino.

A sabedoria da prática. A última fonte da base de conhecimento é a menos estudada e codificada de todas. É a própria sabedoria adquirida com a prática, as máximas que guiam (ou proveem racionalização reflexiva para) as práticas de professores competentes. Uma das tarefas mais importantes para a comunidade acadêmica é trabalhar com os educadores para desenvolver representações codificadas da sabedoria pedagógica adquirida com a prática de professores competentes. Como já dissemos, a maior parte do conceito de ensino expresso neste artigo deriva de coleta, exame e início de codificação da sabedoria que emerge da prática de professores experientes e inexperientes.

O retrato de Nancy, com o qual este ensaio começou, é apenas uma das muitas descrições e análises de ensino excelente que temos coletado nos últimos anos. Ao organizar e interpretar esses dados, tentamos inferir princípios de 
boa prática que podem servir como diretrizes úteis para o esforço de reforma educacional. Tentamos manter os relatos altamente contextualizados, especialmente no que concerne à especificidade do conteúdo a ser ensinado e sua relação com as estratégias pedagógicas empregadas. Assim, contribuímos para a documentação das boas práticas como uma fonte significativa de padrões de ensino. Também tentamos estabelecer uma fundação para a literatura acadêmica que registra os detalhes e as lógicas de práticas pedagógicas específicas.

Uma das frustrações do ensino como ocupação e profissão é a extensa amnésia individual e coletiva, a consistência com que as melhores criações dos educadores são perdidas por seus pares tanto contemporâneos como futuros. Ao contrário de campos como a arquitetura (que preserva suas criações em plantas e edifícios), o direito (que constrói uma literatura de casos com opiniões e interpretações), a medicina (com seus registros e estudos de caso) e até mesmo o xadrez, o bridge ou o balé (com suas tradições de preservar tanto os jogos memoráveis como as performances coreografadas por meio de formas inventivas de notação e registro), o ensino é conduzido sem a audiência de seus pares. Carece de uma história da própria prática.

Sem esse sistema de notação e memória, os passos seguintes, de análise, interpretação e codificação de princípios da prática, são difíceis de dar. De nossa pesquisa com professores de todos os níveis de experiência, concluímos que é extenso o conhecimento potencialmente codificável que pode ser extraído da sabedoria da prática. Os educadores simplesmente sabem muita coisa que nunca sequer tentaram articular. A maior parte da agenda da pesquisa na próxima década será coletar, comparar e interpretar o conhecimento prático dos professores com o propósito de estabelecer uma literatura de casos e codificar seus princípios, precedentes e parábolas (SHULMAN, 1986b). Uma grande parte da agenda da pesquisa associada ao programa Carnegie para desenvolver novas avaliações para professores envolve a realização de estudos do tipo "sabedoria da prática”. Esses estudos registram e organizam em casos o raciocínio e as ações de professores talentosos para estabelecer padrões de prática em áreas específicas do ensino9.

9 Pode-se argumentar que as fontes para um excelente desempenho são geralmente tácitas e não estão disponíveis para o educador. Mas o ensino requer um tipo especial de perícia ou maestria, no qual explicar e mostrar são as principais características. E o conhecimento tácito tem valor limitado entre professores se eles são responsáveis por 
Uma base de conhecimento para o ensino não é fixa e definitiva. Embora ensinar seja uma das profissões mais velhas do mundo, a pesquisa educacional, especialmente o estudo sistemático do ensino, é um empreendimento relativamente novo. Podemos oferecer bons argumentos para justificar as categorias e esquemas abrangentes da base de conhecimento para o ensino. Ficará, porém, muito claro que boa parte - senão a maior parte - da base de conhecimento proposta ainda aguarda para ser descoberta, inventada e refinada. À medida que aprendemos mais sobre o ensino, vamos começar a reconhecer novas categorias de desempenho e compreensão que são características dos bons professores e teremos de reconsiderar e redefinir outros campos. Nossa versão preliminar para a base de conhecimento para o ensino tem muitas células ou categorias com títulos rudimentares, parecendo a tabela periódica da química de há um século. À medida que avançamos, saberemos que algo pode ser conhecido em princípio sobre um certo aspecto do ensino, mas não saberemos ainda o que esse princípio ou prática acarreta. Mesmo assim, acreditamos que os pesquisadores e os melhores professores são capazes de definir, descrever e reproduzir o bom ensino.

OS PROCESSOS DE AÇÃO E RACIOCÍNIO PEDAGÓGICOS

A concepção de ensino que discutirei emergiu de certo número de fontes, tanto filosóficas como empíricas. Uma fonte-chave é composta das dezenas de professores que temos estudado em nossa pesquisa nos últimos três anos. Por meio de entrevistas, observações, atividades e exame de materiais, temos tentado entender como eles trafegam, na ida e na volta, do status de aprendiz para o de professor ${ }^{10}$, de ser capaz de compreender o conteúdo por si mesmo a se tornar capaz de elucidar o conteúdo de novas maneiras, reorganizá-lo e dividi-lo, envolvê-lo em atividades e emoções, em metáforas e exercícios, e em exemplos e demonstrações, de forma que possa ser compreendido pelos alunos.

Na maneira como hoje concebemos o ensino, ele começa com um ato de razão,

explicar, para seus alunos, comunidades e pares, o que fazem e por que o fazem.

10 A metáfora do tráfego não foi usada à toa. Como no trânsito diário entre a casa e o trabalho, a jornada entre o aprendiz e o professor tampouco tem mão única. Os melhores professores, assim como os menos habilidosos, precisam de aprendizado constante para poder ensinar. 
continua com o processo de raciocínio, culmina em ações para transmitir, extrair, envolver ou atrair, e em seguida sofre muita reflexão até o processo começar de novo. Na discussão que se segue, vamos enfatizar o ensino como compreensão e raciocínio, como transformação e reflexão. Essa ênfase se justifica pela determinação com que tanto a pesquisa como as políticas públicas flagrantemente ignoraram esses aspectos do ensino no passado.

Fenstermacher $(1978,1986)$ provê um esquema útil para a análise. $O$ objetivo da formação do professor, diz ele, não é doutrinar ou treinar professores para se comportar da maneira prescrita, mas sim educar professores para refletir em profundidade sobre o próprio ensino, assim como para ter um bom desempenho como docente. A reflexão profunda requer tanto um processo de pensamento sobre o que estão fazendo como uma adequada base de fatos, princípios e experiências, a partir dos quais se raciocina. Os professores precisam aprender a usar sua base de conhecimento para prover fundamentos para escolhas e ações. Portanto, a formação de professores precisa trabalhar com as crenças que guiam as ações docentes, com os princípios e evidências subjacentes às escolhas feitas pelos professores. Essas razões (chamadas "premissas do argumento prático" na análise de Green [1971], na qual Fenstermacher baseia seu próprio argumento) podem ser predominantemente arbitrárias ou idiossincráticas ("Parecia mesmo uma boa ideia na hora!" ou "Não sei muito sobre ensino, mas sei do que gosto"), ou podem repousar sobre princípios éticos, empíricos, teóricos ou práticos que têm apoio substancial entre os membros da comunidade profissional de professores. Fenstermacher argumenta que o bom ensino não pode ser apenas eficaz em termos de desempenho docente, mas também deve repousar sobre premissas adequadamente fundamentadas.

Quando examinamos a qualidade do ensino, a ideia de influenciar as justificativas ou razões para as decisões dos professores enfatiza precisamente o que deve ser enfatizado: as características do raciocínio pedagógico que levam a ações pedagógicas ou podem explicá-las. Devemos ser cautelosos, porém, para não aplicar ênfase indevida nas razões usadas pelos professores para atingir objetivos específicos, em detrimento das justificativas que eles apresentam para selecionar os próprios objetivos. 0 ensino é ao mesmo tempo eficaz e normativo; concerne tanto aos meios quanto aos fins. Processos de raciocínio estão subjacentes a ambos. A base de conhecimento deve, portanto, lidar com os propósitos da educação e também com os métodos e estratégias adotados para educar. 
Esta imagem do ensino envolve a troca de ideias. A ideia é captada, testada e compreendida por um professor, que depois tem de ficar com ela na cabeça, examinando todos os seus lados. Depois, a ideia é formatada ou adaptada até poder ser captada pelos alunos. Este captar, porém, não é um ato passivo. Assim como a compreensão do professor requer uma interação vigorosa com as ideias, espera-se que também os alunos lidem ativamente com as ideias. Com efeito, nossos professores exemplares apresentam ideias de forma a provocar os processos construtivos de seus alunos para não os tornar dependentes do professor nem estimular a imitação adulatória ${ }^{11}$.

Só a compreensão não é suficiente. A utilidade desse conhecimento está no seu valor para julgamento e ação. Portanto, em resposta ao meu aforismo, "os que podem fazem; os que compreendem ensinam" (SHULMAN, 1986b, p. 14), Petrie (1986) corretamente observou que eu não avançara o suficiente. A compreensão, disse ele, deve ser ligada ao julgamento e à ação para que possa ser usada apropriadamente a fim de forjar sábias decisões pedagógicas.

\section{ASPECTOS DO RACIOCÍNIO PEDAGÓGICO}

Parto da premissa de que a maior parte do ensino é iniciada com algum tipo de "texto": um material didático, um programa de estudos ou algum outro material que o professor ou o aluno querem entender. 0 texto pode ser um veículo para a realização de outros propósitos educacionais, mas algum tipo de material de ensino está quase sempre envolvido. A concepção de raciocínio pedagógico exposta a seguir surgiu a partir do ponto de vista do professor, que está diante do desafio de tomar o que já compreende e prepará-lo para um ensino eficaz. 0 modelo de raciocínio e ação pedagógicos está resumido na Tabela 1.

11 A direção e o sequenciamento da instrução também podem ser bem diferentes. Os alunos podem literalmente iniciar o processo, descobrindo, inventando ou investigando, para preparar as próprias representações e transformações. Em seguida, é a vez de o professor responder ativa e criativamente a essas iniciativas estudantis. Em cada caso, o professor precisa ter tanto a compreensão como a capacidade para a transformação. No caso iniciado pelo aluno, a flexibilidade para responder, julgar, nutrir e provocar a criatividade do aluno dependerá das próprias capacidades do professor para interpretação e transformação empáticas. 
Tabela 1 - Um modelo de ação e raciocínio pedagógicos

\begin{tabular}{|c|c|}
\hline Compreensão & $\begin{array}{c}\text { De propósitos, estruturas do conteúdo, ideias dentro } \\
\text { e fora da disciplina. }\end{array}$ \\
\hline \multirow{4}{*}{ Transformação } & $\begin{array}{l}\text { Preparação: interpretação crítica e análise de textos, estruturando } \\
\text { e segmentando, desenvolvimento de um repertório curricular e } \\
\text { esclarecimento de propósitos. }\end{array}$ \\
\hline & $\begin{array}{l}\text { Representação: uso do repertório representacional, que inclui analogias, } \\
\text { metáforas, exemplos, demonstrações, explicações e assim por diante. }\end{array}$ \\
\hline & $\begin{array}{c}\text { Seleção: escolha dentro de um repertório instrucional que inclui modos } \\
\text { de ensinar, organizar, gerenciar e arrumar. }\end{array}$ \\
\hline & $\begin{array}{c}\text { Adaptação e ajuste às características dos alunos: consideração de } \\
\text { conceitos, preconceitos, equívocos e dificuldades, língua, cultura e } \\
\text { motivações, classe social, gênero, idade, habilidade, aptidão, } \\
\text { interesses, autoestima e atenção. }\end{array}$ \\
\hline Instrução & $\begin{array}{l}\text { Gerenciamento, apresentações, interações, trabalho em grupo, } \\
\text { disciplina, humor, questionamentos e outros aspectos do ensino } \\
\text { ativo, instrução de descoberta ou de investigação e as formas } \\
\text { observáveis de ensino em sala de aula. }\end{array}$ \\
\hline Avaliação & $\begin{array}{l}\text { Verificação do entendimento do aluno durante o ensino interativo. } \\
\text { Testar o entendimento do aluno no final das aulas ou unidades. } \\
\text { Avaliar o próprio desempenho e ajustá-lo às experiências. }\end{array}$ \\
\hline Reflexão & $\begin{array}{l}\text { Rever, reconstruir, reconstituir e analisar criticamente o próprio } \\
\text { desempenho e o da classe, e fundamentar as explicações em evidência. }\end{array}$ \\
\hline Novas compreensões & $\begin{array}{l}\text { De propósitos, da matéria, dos alunos, do ensino e de si mesmo. } \\
\text { Consolidação dos novos entendimentos e aprendizagens da experiência. }\end{array}$ \\
\hline
\end{tabular}

Dados um texto, propósitos educacionais e/ou um conjunto de ideias, a ação e o raciocínio pedagógicos envolvem um ciclo de atividades: compreensão, transformação, instrução, avaliação e reflexão ${ }^{12}$. O ponto de partida e de chegada do processo é um ato de compreensão.

Compreensão. Ensinar é, primeiro, entender. Pedimos que o professor compreenda criticamente um conjunto de ideias ou conteúdo a ser ensinado ${ }^{13}$.

12 Sob certas condições, o ensino pode começar com "dado um grupo de alunos". Nos primeiros anos do ensino fundamental ou em salas de reforço ou em outros cenários onde as crianças foram reunidas por razões específicas, o ponto de partida para pensar sobre a instrução pode muito bem ser as características do próprio grupo. Provavelmente, há dias em que o professor necessariamente usa os alunos como ponto de partida.

13 Outras visões do ensino também começam com compreensão, mas partem de outra coisa, em vez de ideias ou texto, a ser ensinada e aprendida. Podem focar na compreensão de um conjunto específico de valores, das características, necessidades, interesses ou propensões de um determinado indivíduo ou de um grupo de alunos. Mas algum tipo de compreensão (ou confusão consciente, espanto, ignorância) sempre iniciará o ensino. 
Esperamos que os professores entendam o que ensinam e, quando possível, entendam-no de muitas maneiras. Devem entender como uma ideia dada relaciona-se com outras ideias dentro do mesmo assunto e também com ideias de outros assuntos.

A compreensão dos propósitos também é essencial aqui. Engajamo-nos no ensino para atingir propósitos educacionais, para realizar objetivos relacionados com o letramento do aluno, com a liberdade do aluno para usare desfrutar, para desenvolver entendimentos, habilidades e valores necessários para funcionar numa sociedade livre e justa. Como professores, também lutamos para equilibrar nossos objetivos de nutrir a excelência individual com finalidades mais gerais, que envolvem igualdade de oportunidade e equidade entre alunos de diferentes históricos e culturas. Embora, na maioria dos casos, o ensino comece com algum tipo de texto e o aprendizado desse texto possa ser um objetivo importante em si mesmo, não devemos perder de vista o fato de que o texto é, frequentemente, um veículo para atingir outros propósitos educacionais. As metas da educação transcendem a compreensão de textos específicos, mas podem ser inatingíveis sem eles.

Dizer que um professor deve antes compreender tanto o conteúdo como os propósitos, no entanto, não distingue especificamente o professor dos não professores. Espera-se que um matemático entenda matemática e que um historiador compreenda história. Mas a chave para distinguir a base de conhecimento para o ensino está na interseção entre conteúdo e pedagogia, na capacidade do professor para transformar o conhecimento de conteúdo que possui em formas que são pedagogicamente poderosas e, mesmo assim, adaptáveis às variações em habilidade e histórico apresentadas pelos alunos. Agora vamos discutir a transformação e seus componentes.

Transformação. Ideias compreendidas precisam ser transformadas de alguma maneira para serem ensinadas. Para encontrar seu caminho por meio do ato de ensinar, o professor deve pensar no caminho entre o conteúdo que entendeu e as mentes e motivações dos alunos. Transformações, portanto, requerem alguma combinação ou ordenação dos seguintes processos, cada um dos quais emprega algum tipo de repertório: (1) preparação (dos dados materiais de texto), incluindo o processo de interpretação crítica; (2) representação das ideias na forma de novas analogias, metáforas e assim por diante; (3) seleções instrucionais num leque de métodos e modelos de ensino; e (4) adaptação dessas representações para as características gerais dos jovens em sala de aula. Essas formas de transformação, esses aspectos do processo pelo qual se 
vai da compreensão pessoal à preparação da compreensão por outrem são a essência do ato de raciocinar pedagogicamente, do ensinar como pensamento e do planejar - implícita ou explicitamente - o exercício da docência.

A preparação envolve examinar e interpretar criticamente os materiais de instrução, em termos da compreensão do conteúdo pelo próprio professor (BEN-PERETZ, 1975). Ou seja, examina-se o material de ensino à luz da própria compreensão para verificar se ele "é apropriado para ser ensinado". Este processo de preparação geralmente inclui (1) detectar e corrigir erros por ação ou omissão no texto e (2) os processos cruciais de estruturar e segmentar o material em formas mais bem adaptadas à compreensão do professor e, em perspectiva, mais adequadas ao ensino. Também se detalham os propósitos e metas educacionais. Encontramos exemplos desse processo de preparação em vários de nossos estudos. A preparação baseia-se na disponibilidade de repertório curricular, uma boa ideia do leque de materiais instrucionais, programas e conceitos.

A representação envolve pensar nas ideias-chave do texto ou aula e identificar as maneiras alternativas de representá-las para os alunos. Quais analogias, metáforas, exemplos, demonstrações, simulações e similares podem ajudar a construir uma ponte entre a compreensão do professor e aquela desejada para os alunos? Múltiplas formas de representação são desejáveis. Falamos da importância do repertório representacional nesta atividade ${ }^{14}$.

Seleções instrucionais ocorrem quando o professor precisa ir da reformulação do conteúdo por meio de representações para a incorporação de representações em formas ou métodos instrucionais. Aqui, o professor escolhe de um repertório instrucional de abordagens ou estratégias de ensino. Esse repertório pode ser muito rico, incluindo não apenas as alternativas mais convencionais, como leitura, demonstração, recitação ou trabalho individual na carteira, mas também várias formas de aprendizado cooperativo, ensino recíproco, diálogo, aprendizado por descoberta, métodos de projeto e aprender fora do cenário da sala de aula.

14 A centralidade da representação em nossa concepção do raciocínio pedagógico é importante para relacionar nosso modelo de ensino a abordagens mais gerais do estudo do pensamento humano e da solução de problemas. Psicólogos cognitivos (por exemplo, GARDNER, 1986; MARTON, 1986; NORMAN, 1980) argumentam que processos de representação interna são elementos-chave para qualquer psicologia cognitiva. "Para mim, a maior realização da ciência cognitiva foi a demonstração clara da validade de colocar um nível de representação mental: um conjunto de construtos que podem ser invocados para a explicação de fenômenos cognitivos, variando da percepção visual à compreensão de histórias" (GARDNER, 1986, p. 383). Essa ligação entre modelos de pedagogia e modelos mais gerais de funcionamento cognitivo pode servir como estímulo ao necessário estudo do pensamento do professor. 
Adaptação é o processo de ajustar o material representado às características dos alunos. Quais são os aspectos relevantes de aptidão, gênero, linguagem, cultura, motivações ou conhecimentos e habilidades adquiridos anteriormente pelos alunos e que vão afetar suas respostas a diferentes formas de representação e apresentação? Quais concepções, equívocos, expectativas, motivos, dificuldades ou estratégias dos alunos podem influenciar as maneiras como abordarão, interpretarão e entenderão bem ou mal o material? A adequação está relacionada com a adaptação e se refere a adequar o material a alunos específicos na sala de aula, em vez de adequá-lo aos alunos em geral. Quando um professor pensa sobre ensinar alguma coisa, a atividade pode ser comparada com a analogia da manufatura de uma roupa. Adaptação é como preparar a roupa para um estilo, cor e tamanho específicos, de forma que possa ser pendurada num cabide. Quando a roupa está pronta para ser comprada por um cliente específico, porém, precisa ser adequada ao corpo dele para vestir perfeitamente.

Além disso, a atividade do ensino raramente envolve um único aluno por vez, o que seria definido pelo termo especial “tutoria”. Quando falamos de ensinar em circunstâncias escolares típicas, descrevemos a atividade que traz instrução a grupos de pelo menos 15 alunos - ou, mais genericamente, 25 ou 35. Portanto, a adequação da instrução envolve adequar representações não apenas para alunos específicos, mas também para um grupo de certo tamanho, disposição, receptividade e “química” interpessoal.

Todos esses processos de transformação resultam num plano ou conjunto de estratégias para apresentar uma aula, unidade ou curso. Até agora, evidentemente, foi tudo um ensaio para o ato de ensinar, que ainda não ocorreu. 0 raciocínio pedagógico é tão parte do ensino quanto o próprio ato de ensinar. 0 raciocínio não para quando a instrução começa. As atividades de compreensão, transformação, avaliação e reflexão continuam a ocorrer durante o ensino ativo. 0 próprio ensino torna-se um estímulo para a ponderação e a ação. Portanto, tratamos em seguida do ensino que consuma todo esse raciocínio no ato da instrução.

Instrução. Essa atividade envolve o desempenho observável de vários atos de ensino. Inclui muitos dos aspectos mais cruciais da pedagogia: organizar e gerenciar a sala de aula; apresentar explicações claras e descrições vívidas; atribuir e verificar trabalhos; e interagir eficazmente com os alunos por meio de perguntas, respostas e reações, além de elogio e crítica. Inclui, portanto, gestão, explicação, discussão e todas as características observáveis da instrução direta e heurística eficaz, já bem documentadas na literatura da pesquisa sobre ensino eficaz. 
Temos boas razões para acreditar que há forte relação entre a compreensão do conteúdo de um professor e os estilos de ensino empregados. Um exemplo, baseado na pesquisa de Grossman (1985), vai ilustrar este ponto.

Colleen completou um mestrado em Inglês antes de entrar no programa de formação de professores. Ela tinha confiança no seu domínio do conteúdo e começou seu estágio com entusiasmo e energia. Sua visão da literatura e seu ensino eram altamente interpretativos e interativos. Ela via a boa literatura como uma comunicação em camadas, capaz de muitas leituras e interpretações diversas. Além disso, achava que essas várias leituras deveriam aparecer por meio de seus alunos, através da leitura cuidadosa que eles mesmos fizessem dos textos.

Colleen estava tão comprometida com a ideia de ajudar seus alunos a aprender a ler textos cuidadosamente, um hábito mental nem sempre encontrado entre jovens ou idosos, que construiu um dever de casa em que cada aluno era solicitado a trazer para a escola a letra de uma canção favorita de rock. (Ela deve ter percebido que algumas dessas letras eram de gosto duvidoso, mas preferiu maximizar a motivação em vez de usar discrição nessa unidade específica.) Então, pediu a eles para reescrever cada linha da canção, usando sinônimos ou paráfrases para substituir cada palavra original. Para muitos, foi a primeira vez que olharam qualquer texto com tanta atenção.

Quando ensina um texto de literatura, Colleen funciona de maneira altamente interativa, extraindo ideias dos alunos sobre uma frase ou uma fala, aceitando múltiplas interpretações desde que o aluno pudesse defender sua opinião com referências ao próprio texto. Com base nessas observações, poder-se-ia caracterizar o estilo de ensino de Colleen com adjetivos como centrada no aluno, baseada em discussão, ocasionalmente socrática ou altamente interativa.

Muitas semanas mais tarde, contudo, observamos Colleen ensinando uma unidade de gramática. Embora tivesse duas formações de nível superior em Inglês, Colleen quase não foi preparada em gramática. No entanto, como uma típica classe de inglês no nível médio deve incluir alguma gramática, além de literatura e redação, era impossivel evitar ensinar essa matéria. Ela estava um pouco ansiosa na entrevista pré-observação.

Colleen parecia outra professora durante essa aula. Seu estilo interativo evaporou. Em seu lugar estava uma combinação de palestra com recitação altamente controlada,

altamente didática, dirigida pelo professor, de ritmo acelerado: Distar ${ }^{15}$ no lugar de Sócrates. Às vezes, refiro-me a esse tipo de aula como estilo almirante Farragut:

"Danem-se as perguntas! Toda velocidade à frente!"”6 Os alunos não tiveram oportunidade de fazer perguntas ou oferecer pontos de vista alternativos. Depois da aula, ela confessou ao observador que passou o tempo todo

15 Sigla de Direct Instruction Strategies for Teaching Arithmetic and Reading (estratégias de instrução direta para ensinar aritmética e leitura), um programa de ensino patenteado por uma grande editora comercial. (N. da T.)

16 O almirante David Glasgow Farragut (1801-1870), da Marinha dos Estados Unidos, ficou famoso por sua frase na batalha da baía de Mobile, durante a Guerra Civil: "Danem-se os torpedos! Toda velocidade à frente!" (N. da T.) 
tentando evitar olhar para um aluno específico, sentado na fileira da frente, porque esse jovem sempre fazia boas perguntas ou tinha boas ideias, e nesta aula em particular Colleen não queria encorajar nada disso, porque ela não tinha certeza das respostas. Ela estava insegura sobre o conteúdo e adaptou seu estilo de instrução para aliviar sua ansiedade ${ }^{17}$.

O caso de Colleen ilustra as maneiras como o comportamento docente está intimamente ligado à compreensão do conteúdo e à transformação do entendimento. As técnicas de ensino flexíveis e interativas que ela usa não podem ser usadas quando ela não entende do assunto a ser ensinado. Tendo examinado os processos de raciocínio e desempenho pedagógicos de natureza prospectiva e ativa ${ }^{18}$, vamos examinar agora os retrospectivos.

Avaliação. Esse processo inclui a verificação imediata da compreensão e dos mal-entendidos que um professor deve usar para ensinar interativamente, assim como os testes e avaliações mais formais que os professores fazem para organizar portfólios e notas. É claro que a verificação dessa compreensão requer todas as formas de compreensão do conteúdo pelo professor e de transformação descritas acima. Entender o que um aluno entende requer um domínio profundo tanto do material a ser ensinado como dos processos de aprendizado. Essa compreensão precisa ser específica para cada matéria escolar e para tópicos individuais dentro da matéria. Isso representa outra forma de usar o que chamamos de conhecimento pedagógico do conteúdo. Avaliamse também o próprio ensino do professor e as aulas e materiais empregados nessas atividades. Nesse sentido, a avaliação leva diretamente à reflexão.

Reflexão. Isso é o que faz um professor quando olha para o ensino e o aprendizado que acabaram de ocorrer e reconstrói, reencena e/ou recaptura os eventos, as emoções e as realizações. É por meio desse conjunto de processos que um profissional aprende com a experiência. Pode ocorrer sozinho, com a ajuda de dispositivos de gravação ou apenas com a memória. Aqui, de novo, é provável que a reflexão não seja apenas um estado de espírito (como em "ah, ele é uma pessoa tão reflexiva!") ou um conjunto de estratégias, mas

17 De forma alguma quero insinuar que palestras eficazes não têm lugar na sala de aula no ensino médio. Ao contrário, boas palestras são uma técnica indispensável de ensino. Neste caso, estou mais interessado na relação entre conhecimento e ensino. Podese ponderar que este estilo de ensino é mais adequado para gramática do que para literatura, porque há pouco para discutir ou interpretar numa aula de gramática. Não concordo, mas não vou me aprofundar no assunto aqui. No caso de Colleen, a lógica para uma palestra linear não tinha fundamento nesse argumento, mas claramente resultava de sua preocupação em limitar o espaço para desvios do caminho que ela tinha traçado.

18 Enactive no original em inglês, aqui traduzido por "ativo", é um termo cunhado por J. Bruner em sua teoria do desenvolvimento do pensamento representativo. As representações "ativas" baseiam-se na ação e no movimento e são mais primitivas do que as representações icônicas e simbólicas. (N. da T.) 
também o uso de certos tipos de conhecimento analítico aplicados ao trabalho pessoal (RICHERT, em preparação). Nesse processo, é crucial revisar o ensino em comparação com os objetivos buscados.

Nova compreensão. Assim, chegamos ao novo começo, à expectativa de que, por meio de atos de ensino "pensados" e "lógicos", o professor atinja uma nova compreensão, tanto dos propósitos e dos conteúdos a serem ensinados como dos alunos e dos próprios processos didáticos. Há muitos momentos transitórios de aprendizado entre os professores que podem ser caracterizados pelo “arrá!” de um momento de descoberta que nunca é consolidado e incorporado em um novo entendimento ou em um repertório renovado (BRODKEY, 1986). A nova compreensão não ocorre automaticamente, mesmo depois de avaliação e reflexão. São necessárias estratégias específicas para documentação, análise e discussão.

Embora os processos neste modelo sejam apresentados de forma sequencial, eles não pretendem representar um conjunto de etapas, fases ou passos fixos. Muitos dos processos podem ocorrer numa ordem diferente. Alguns podem nem ocorrer durante alguns atos de ensino. Alguns podem ser truncados, outros, elaborados. No ensino primário, por exemplo, podem ocorrer alguns processos que são ignorados ou apenas mencionados neste modelo. Mas um professor precisa demonstrar a capacidade de adotar esses processos quando solicitado e a formação de professores deve prover estes com as formas de compreensão e as habilidades de ensino de que eles precisarão para progredir mediante o raciocínio e conseguir executar um ato completo de pedagogia, como representado aqui.

CONHECIMENTO, POLÍTICA DE ENSINO E REFORMA EDUCACIONAL

As pesquisas, deliberações e debates sobre o que os professores precisam saber e saber fazer nunca foram tão ativas. Há esforços de reforma em andamento: variam da elevação dos requerimentos para admissão a programas de formação de professores ao estabelecimento de avaliações nacionais e estaduais para professores; da insistência em que a preparação de professores requer pelo menos cinco anos de educação superior (porque há tanto a aprender) à organização de sofisticados programas de indução e tutoria de novos professores (porque o aprendizado e a socialização mais importantes só podem ocorrer no local de trabalho). 
A maioria das reformas atuais repousa no apelo à maior profissionalização da docência, com padrões mais altos de admissão, maior ênfase nas bases acadêmicas da formação, programas mais rigorosos de preparação prática e teórica, melhores estratégias de certificação e licenciamento, e transformações no local de trabalho que permitam maior autonomia e liderança do professor. Em grande medida, essas reformas querem que o ensino siga o modelo de outras profissões que definem suas bases de conhecimento em termos sistemáticos, requerem longos períodos de preparação, socializam neófitos na prática com extensos períodos de estágio ou residência, e empregam procedimentos muito exigentes de certificação nacional e estadual.

Concepções da competência do professor estão implícitas em todas essas reformas. Parâmetros de formação e avaliação de professores são necessariamente baseados em imagens do ensino e de suas demandas. A concepção de base de conhecimento para o ensino, apresentada neste artigo, difere de maneira significativa de muitas outras que existem na comunidade formuladora de políticas. A ênfase nas relações integrais entre ensino e as áreas acadêmicas disciplinares torna claro que a formação de professores é responsabilidade de toda a universidade, não apenas das escolas ou departamentos de educação. Além disso, os professores não podem ser adequadamente avaliados pela observação de seu desempenho em classe sem referência ao conteúdo que estão ensinando.

A concepção de raciocínio pedagógico enfatiza a base intelectual para o desempenho docente e não apenas olha isoladamente para o comportamento do professor. Se esta concepção for levada a sério, tanto a organização como o conteúdo dos programas de formação de professores e a definição dos fundamentos acadêmicos dessa formação vão precisar de revisão. Programas de formação de professores já não poderão limitar sua atividade às áreas de didática e de supervisão da prática que não levam em consideração o conteúdo. Uma ênfase no conhecimento pedagógico do conteúdo permearia o currículo de formação de professores. Um exame dos professores por um conselho nacional focalizaria na habilidade do professor para pensar sobre o ensino, para ensinar tópicos específicos e para basear suas ações em premissas que podem ser escrutinadas pela comunidade profissional.

Temos o dever de elevar os padrões no interesse do aperfeiçoamento, mas também devemos evitar a criação de ortodoxias rígidas. Precisamos elaborar padrões sem padronização. Precisamos tomar cuidado para que a abordagem baseada em conhecimento não produza uma imagem excessivamente técnica do ensino, um empreendimento científico que perdeu sua alma. Os 
problemas mais sérios da medicina e de outras profissões da área de saúde surgem quando os médicos tratam a doença e não a pessoa, ou quando as necessidades de trabalho ou pessoais do profissional têm precedência sobre suas responsabilidades para com os pacientes.

A necessária mudança, porém, não pode ocorrer sem riscos. As atuais definições incompletas e triviais do ensino, que são adotadas pela comunidade formuladora de políticas, contêm um perigo muito maior para a boa educação do que a tentativa mais séria de formular a base de conhecimento. Nancy representa um modelo de excelência pedagógica que deveria se tornar a base para as novas reformas. Um entendimento apropriado da base de conhecimento para o ensino, das fontes para esse conhecimento e das complexidades do processo pedagógico tornará mais provável o surgimento desse tipo de professor. 


\section{Knowledge and teaching: foundations of the new reform}

Abstract: Lee S. Shulman builds his foundation for teaching reform on an ideia of teaching that emphasizes comprehension and reasoning, transformation and reflection. "This emphasis is justified", he writes, "by the resoluteness with which research and policy have so blatantly ignored those aspects of teaching in the past”. To articulate and justify this conception, Shulman responds to four questions: What are the sources of the knowledge base for teaching? In what terms can these sources be conceptualized? What are the processes of pedagogical reasoning and action? and What are the implications for teaching policy and educational reform? The answers - informed by philosophy, psychology, and a growing body of case-work based on young and experienced practitioners - go far beyond current reform assumptions and initiatives. The outcome for educational practitioners, scholars, and policymakers is a major redirection in how teaching is to be understood and teachers are to be trained and evaluated.

Keywords: Teaching education. Educational policy. Teaching. Pedagogy. 


\section{REFERÊNCIAS}

BAXTER, J. Teacher explanations in computer programming: a study of knowledge transformation. Tese de doutorado. Universidade Stanford, Stanford, em preparação.

BEN-PERETZ, M. The concept of curriculum potential. Curriculum Theory Network, v. 5, p. 151-159, 1975.

BERLINER, D. In pursuit of the expert pedagogue. Educational Researcher, v. 15, n. 7, p. 5-13, 1986.

BLOOM, B. S. Human characteristics and school learning. Nova York: McGrawHill, 1976.

BRODKEY, J. J. Learning while teaching: self-assessment in the classroom. 1986. Tese de doutorado. Universidade Stanford, Stanford, 1986.

BROPHY, J. J.; GOOD, T. Teacher behavior and student achievement. In: WITTROCK, M. C. (Ed.). Handbook of research on teaching. 3. ed. Nova York: Macmillan, 1986. p. 328-375.

Carnegie Task Force on Teaching as a Profession. A nation prepared: teachers for the $21^{\text {st }}$ entury. Washington, DC: Carnegie Forum on Education and the Economy, 1986.

CLEMENT, J. Student' preconceptions in introductory mechanics. American Journal of Physics, v. 50, p. 67-71, 1982.

DEWEY, J. The relation of theory to practice in education. In: McMurry, C. A. (Ed.). The relation of theory to practice in the education of teachers. Bloomington, IL: Public School Publishing, 1904. (Terceiro Livro do Ano da National Society for the Scientific Study of Education, Parte I).

ERLWANGER, S. H. Case studies of children's conceptions of mathematics, Part I. Journal of Children's Mathematical Behavior, v. 1, p. 157-283, 1975.

FENSTERMACHER, G. A philosophical consideration of recent research on teacher effectiveness. In: SHULMAN, L. S. (Ed.). Review of research on education. Itasca, IL: Peacock, 1978. v. 6, p. 157-185.

Philosophy of research on teaching: three aspects. In: Wittrock, M. C. (Ed.). Handbook of research on teaching. 3. ed. Nova York: Macmillan, 1986. p. 37-49. 
GAGE, N. L. The scientific basis of the art of teaching. Nova York: Teacher College Press, 1978.

Hard gains in the soft sciences: the case of pedagogy. Bloomington, IN: Phi Delta Kappa, 1986.

GARDNER, $\mathrm{H}$. The mind's new science: a history of cognitive revolution. Nova York: Basic Books, 1986.

GREEN, T. F. The activities of teaching. Nova York: McGraw-Hill, 1971.

GROSSMAN, P. A passion for language: from text to teaching. Stanford: Universidade Stanford, Escola de Educação, 1985. (Knowledge Growth in Teaching Publications Series).

GUDMUNDSDOTTIR, S. Knowledge use among experienced teachers: four case studies of high school teaching. 1988. Tese de doutorado. Universidade Stanford, Stanford, 1988.

HASHWEH, M. Z. An exploratory study of teacher knowledge and teaching: the effects of science teachers' knowledge of subject-matter and their conceptions of learning on their teaching. 1985. Tese de doutorado. Universidade Stanford, Stanford, 1985.

HOLMES GROUP, THE. Tomorrow's teachers: a report of the Holmes Group. East Lansing, MI: Author, 1986.

LEINHARDT, G. Novice and expert knowledge of individual student's achievement. Educational Psychologist, v. 18, p. 165-179, 1983.

; Greeno, J. G. The cognitive skill of teaching. Journal of Educational Psychology, v. 78, p. 75-95, 1985.

; Smith, D. A. Expertise in mathematics instruction: subject matter knowledge. Journal of Educational Psychology, v. 77, p. 247-271, 1986.

MARTON, F. Towards a pedagogy of content. Manuscrito não publicado. Suécia: University of Gothenburg, 1986.

NORMAN, D. A. What goes on in the mind of the learner? In: MCKEACHIE, W. J. (Ed.). New directions for teaching and learning: learning, cognition, and college teaching. San Francisco: Jossey-Bass, 1980. v. 2.

PETRIE, $H$. The liberal arts and sciences in the teacher education curriculum. Trabalho apresentado em: Conference on Excellence in Teacher Preparation through the Liberal Arts, Muhlenberg College, Allentown, PA, maio 1986. 
RICHERT, A. Reflex to reflection: facilitating reflection in novice teachers. Tese de doutorado. Stanford University: Stanford, em preparação.

ROSENSHINE, B. Unsolved issues in teaching content: a critique of a lesson on federalist paper n. 10. Trabalho apresentado em: Reunião da American Educational Research Association, San Francisco, CA, abr. 1986.

; Stevens, R. S. Teaching functions. In: Wittrock, M. C. Handbook of research on teaching. 3 ed. Nova York: Macmillan, 1986. p. 376-391.

ROSENTHAL, R.; Jacobson, L. Pygmalion in the classroom. Nova York: Holt, Rinehart \& Winston, 1968.

SCHEFFLER, I. Conditions of knowledge: an introduction to epistemology and education. Chicago: University of Chicago Press, 1965.

SCHWAB, J. J. The structure of the disciplines: meanings and significances. In: Ford, G. W.; Pugno, L. (Eds.). The structure of knowledge and the curriculum. Chicago: Rand McNally, 1964.

. The practical four: something for curriculum professors to do. Curriculum Inquiry, v. 13, p. 239-265, 1983.

SHULMAN, L. S. Paradigms and research programs for the study of teaching. In: M. C. Wittrock (Ed.). Handbook of research on teaching. 3. ed. Nova York: Macmillan, 1986a. p. 3-36.

. Those who understand: knowledge growth in teaching. Educational Researcher, v. 15, n. 2, p. 4-14, 1986b.

; Keislar, E. R. (Eds.). Learning by discovery: a critical appraisal. Chicago: Rand McNally, 1966.

; Sykes, G. A national board for teaching? In: Search of a bold standard. Trabalho apresentado por: Task Force on Teaching as a Profession, Carnegie Forum on Education and the Economy, mar. 1986.

SMITH, B. O. A design for a school of pedagogy. Washington, DC: U.S. Department of Education, 1980.

SYKES, G. The social consequences of standard-setting in the professions. Trabalho apresentado por: Task Force on Teaching as a Profession, Carnegie Forum on Education and the Economy, 1986.

WILSON. S. M.; SHULMAN, L. S.; RICHERT, A. 150 different ways' of knowing: representations of knowledge in teaching. In: Calderhead, J. (Ed.). Exploring teacher thinking. Sussex: Holt, Rinehart \& Winston, no prelo. 
